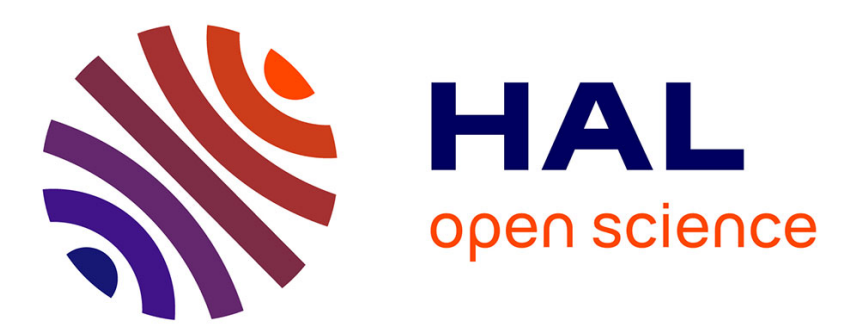

\title{
In vivo effectiveness of carbonated calcium-deficient hydroxyapatite-coated activated carbon fiber cloth on bone regeneration
}

Florian Olivier, Vincent Sarou-kanian, Franck Fayon, Sylvie Bonnamy, Nathalie Rochet

\section{To cite this version:}

Florian Olivier, Vincent Sarou-kanian, Franck Fayon, Sylvie Bonnamy, Nathalie Rochet. In vivo effectiveness of carbonated calcium-deficient hydroxyapatite-coated activated carbon fiber cloth on bone regeneration. Journal of Biomedical Materials Research Part B: Applied Biomaterials, 2021, 10.1002/jbm.b.34986 . hal-03474712

\section{HAL Id: hal-03474712 \\ https://hal.science/hal-03474712}

Submitted on 10 Dec 2021

HAL is a multi-disciplinary open access archive for the deposit and dissemination of scientific research documents, whether they are published or not. The documents may come from teaching and research institutions in France or abroad, or from public or private research centers.
L'archive ouverte pluridisciplinaire $\mathbf{H A L}$, est destinée au dépôt et à la diffusion de documents scientifiques de niveau recherche, publiés ou non, émanant des établissements d'enseignement et de recherche français ou étrangers, des laboratoires publics ou privés. 


\title{
In vivo effectiveness of carbonated calcium-deficient hydroxyapatite-coated activated carbon fiber cloth on bone regeneration
}

\author{
F. Olivier ${ }^{\text {a }}$, V. Sarou-Kanian ${ }^{\mathrm{b}}$, F. Fayon ${ }^{\mathrm{b}}$, S. Bonnamy ${ }^{\mathrm{a}}$, N. Rochet ${ }^{\mathrm{c}}$ \\ ${ }^{\text {a }}$ CNRS, Univ. Orléans, ICMN UMR 7374, Orléans, France \\ ${ }^{\mathrm{b}}$ CNRS, Univ. Orléans, CEMTHI UPR 3079, Orléans, France \\ ${ }^{c}$ Univ. Côte d'Azur, CNRS, INSERM, iBV, Nice, France
}

\begin{abstract}
We have previously shown that activated carbon fiber cloth (ACC) either uncoated or coated with carbonated calcium-deficient hydroxyapatite (CDA), namely ACC and ACC/CDA, were biocompatible in vitro with human osteoblasts. Here we hypothesized that ACC and ACC/CDA could be used as tissue patches in vivo to accelerate wounded bone healing. In a model of rat femoral defect, we have compared spontaneous cortical bone regeneration with regeneration in the presence of ACC and ACC/CDA patches. At day 7, 14 and 21, bone formation was evaluated using micro computed tomography $(\mu \mathrm{CT})$, magnetic resonance imaging (MRI) and histological analysis. Our results demonstrate first that these ACC tissues are highly biocompatible in vivo, and second that ACC/CDA patches apposition results in the acceleration of bone reconstruction due to a guiding action of the ACC fibers and an osteogenic effect of the CDA phase. We guess that this approach may represent a valuable strategy to accelerate bone regeneration in human.
\end{abstract}

Key words: Bone healing, Patches, Guided bone regeneration, Activated carbon fiber cloth, Biomimetic carbonated calcium-deficient hydroxyapatite. 


\section{Introduction}

Activated carbon fiber cloth (ACC) are obtained by weaving, carbonization and activation of organic polymers. The nature of the polymer precursor and the carbonization parameters lead to a high variety of carbon fibers (CFs) and thus of ACC [1-3]. ACC materials have a high specific surface area and a high micro porosity [4,5], which properties allow to use them as absorbent in the gaseous or in the liquid phase for various applications such as adsorption and water purification [6-8].

In the late 1970s and 1980s CFs and more specifically ACC were proposed as biomaterials in the field of bone regeneration [9-11]. In 1978, Adams et al. described the biocompatibility of a carbon/carbon composite composed of carbon fiber-reinforced carbon. After 14 weeks of implantation into holes drilled transversely through rat femora, histological analysis revealed no inflammatory reaction [9]. In 1982, Minns et al. showed in rabbit that CFs patches made of filaments containing 2000 fibers of $9 \mu \mathrm{m}$ diameter could promote the healing of osteochondral defects in osteoarthritic knees [10]. In 1989, the same authors, suggested that the use of CFs patches could be attractive in the long term by decreasing friction and subsequent degeneration and wear commonly seen in fibrillated, disrupted articular cartilage [11]. In 2000, CarranzaBencano et al. also used CFs to fill 5-mm drilled osteochondral defects in rabbit patella. In this long term study the authors observed that fibrous tissue evolved into fibrocartilage after 9 months and into hyaline cartilage in after 1 year. They concluded that, in rabbits, CFs could be used to repair articular cartilage defects of the patella [12].

Since the 2000s, CFs are also used to improve the mechanical properties of calcium phosphates (CaPs) [13-17] such as hydroxyapatite (HA) whose application as load-bearing implant material is limited due to brittleness [18-21].

Our previous studies demonstrated the possibility to coat different $\mathrm{CaP}$ phases on ACC surface by sono-electrodeposition with a total control of process [22,23]. We selected a combination of 
biocompatible ACC and biomimetic coating of carbonated calcium-deficient hydroxyapatite (CDA) whose biocompatibility was validated with human primary osteoblasts [24].

In the present work we hypothesized that patches of ACC, uncoated or coated with CDA, could have a beneficial effect on cortical bone regeneration by simple apposition at the surface of a bone defect. To test this hypothesis, ACC and ACC/CDA patches were prepared and placed at the surface of cortical defects drilled in rat femurs. Biocompatibility and bone healing were evaluated after 7, 14 and 21 days comparatively to spontaneous regeneration.

\section{Experimental}

\subsection{ACC and ACC/CDA materials}

Activated carbon fiber cloth (ACC), referred as FM50K, was prepared from a viscose precursor supplied by the Zorflex ${ }^{\circledR}$ company. Prior to coating, ACC was washed for $12 \mathrm{~h}$ in boiling distilled water using a Soxhlet ${ }^{\circledR}$ extractor, and dried at $70{ }^{\circ} \mathrm{C}$ under vacuum. Carbonated calcium-deficient hydroxyapatite (CDA) coating was carried out using a sono-electrodeposition process at cathodic polarization $\left(-1 \mathrm{~V} / \mathrm{Hg} / \mathrm{Hg}_{2} \mathrm{SO}_{4}\right)$ and $70{ }^{\circ} \mathrm{C}$ for $6 \mathrm{~h}$. The ACC characteristics (architecture, morphology, microtexture, structure, multi-scale porosity, elemental composition and surface chemistry), as well as the coating ones (thickness, morphology, crystallographic structure, chemical composition of the CaP phase) are detailed in our previous studies [22-24]. Patches of ACC and ACC/CDA were cut and adjusted to bone defect size (10x4 mm) and sterilized by dry heat at $180{ }^{\circ} \mathrm{C}$ for $2 \mathrm{~h}$.

\subsection{In vivo assessment}

\subsubsection{Study design}

All animal procedures obtained the approval of the local animal health care committee (Authorization APAFIS\#19215-2019021512224201). A bilateral femoral defect was created on 36 male Lewis rats weighing $288 \pm 22 \mathrm{~g}$ (Janvier Labs, Le Genest- Saint- Isle, France). The experimental design of this study is described in the Fig. 1. The 72 femurs were randomized 
into three groups (Table 1) corresponding to ACC, ACC/CDA and control (without patch), and in four time points namely day 7, 14 and 21 .

Table 1: Repartition of the femurs into the three groups ACC, ACC/CDA and control at the four timepoints. The first number indicates the number of femurs available for complete evaluation and the second corresponds to the total number of operated femurs.

\begin{tabular}{c|ccc}
$\begin{array}{r}\text { Time points } \\
\text { (day) }\end{array}$ & d7 & d14 & d21 \\
\hline Control & $8 / 8$ & $7 / 8$ & $8 / 8$ \\
ACC & $7 / 8$ & $7 / 8$ & $8 / 8$ \\
ACC/CDA & $8 / 8$ & $7 / 8$ & $8 / 8$ \\
\hline
\end{tabular}

(A)
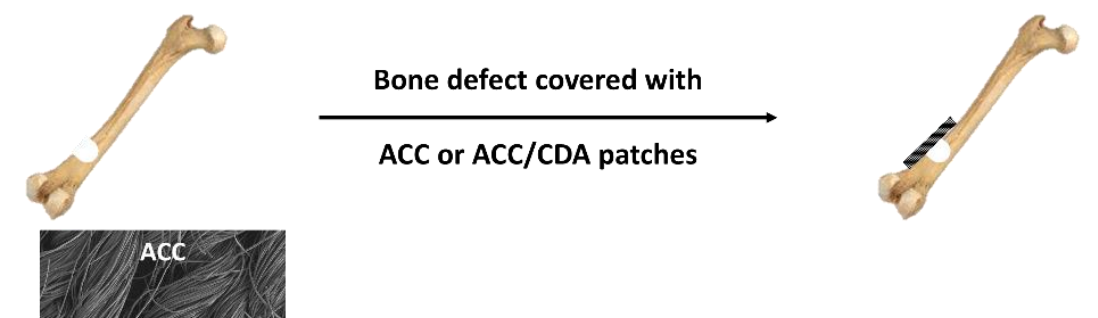

(B)

(C)

(E)

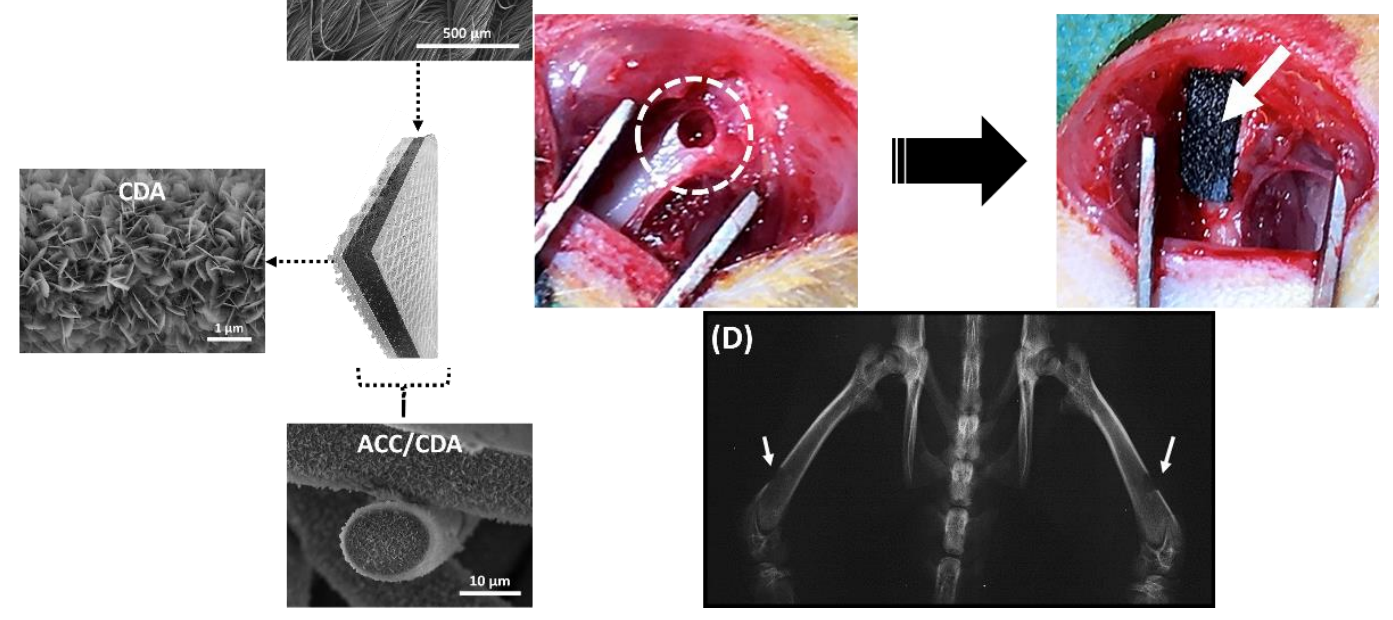

Fig. 1 Experimental design of the study performed in rat femur. (A) Schematic representation of the femoral defect (left) covered with an ACC or ACC/CDA patch (right); (B) SEM images and schematic representation of the different components of ACC and ACC/CDA materials; (C) Representative picture of a femoral defect (white circle, control group); (D) Radiographic view of a bilateral femoral defect immediately after surgery (white arrows); (E) Picture of a patch covering the bone defect (white arrow) in the ACC and ACC/CDA groups. 


\subsubsection{Anesthesia}

Anesthesia induction was done by inhalation of $5 \%$ isoflurane and maintained by intramuscular injection of $30 \mathrm{mg} / \mathrm{kg}$ ketamine (Virbac, Carros, France) and $7.6 \mathrm{mg} / \mathrm{kg}$ xylasine (Dechra, Montigny-le-Bretonneux, France) completed by a subcutaneous injection of $0.1 \mathrm{mg} / \mathrm{kg}$ robinulV (Vetoquinol, Magny-vernois, France) and by intraperitoneal injection of $0.036 \mathrm{mg} / \mathrm{kg}$ buprenorphine (Bubrecare®, Axience, Pantin, France).

\subsubsection{Surgical procedure}

The operation procedure was performed in strict aseptic conditions. The rats were positioned in lateral decubitus and maintained under a mixture of oxygen $(2 \mathrm{~L} / \mathrm{min})$ and air $(5 \mathrm{~L} / \mathrm{min})$. A bilateral cylindrical cavity was created in the distal femoral metaphysis as follows (Fig. 1A, $1 \mathrm{C}$ and 1D). First the two limbs were shaved, the skin was disinfected with iodine solution and the animal was sterile draped. After lateral skin incision, the distal part of the femur was exposed. A cylindrical defect of $2.7 \mathrm{~mm}$ diameter and 4-5 $\mathrm{mm}$ depth including the periosteum was created using a motor-driven drill (Advetis Medical, Montreuil, France) and successive burs of 1.1, 1.5, and $2.7 \mathrm{~mm}$ diameter. During drilling, the site was irrigated using sterile saline. Bone reaming debris were removed by saline irrigation. The defect was then covered with an ACC or ACC/CDA patch (Fig. 1E, white arrow), excepted in the control group where it was left uncovered (Fig. 1C white circle). Surrounding structures were then guided back into their natural anatomic positions until muscles and skin were closed by sutures.

\subsubsection{Postoperative care}

Postoperative pain and walking was assessed every day during the first week and then three times a week. Buprenorphine (Buprecare ${ }^{\circledR}$ ) was administered orally during 6 postoperative days $(135 \mu \mathrm{L} / 100 \mathrm{~mL}$ the first 3 days and $70 \mu \mathrm{L} / 100 \mathrm{~mL}$ the 3 following days); Meloxicam (Metacam ${ }^{\circledR}$, Boehringer Ingelheim, Paris, France) was administered orally during 2 
postoperative days $(135 \mu \mathrm{L} / 100 \mathrm{~mL})$ and an antibiotic (Baytril®, Bayer, La Garenne-Colombe, France) was administered orally during the 5 postoperative days $(200 \mu \mathrm{L} / 100 \mathrm{~mL}$ starting at day 2). The animals were kept in individual cages during the first postoperative week. Any abnormality such as swelling or persistent lameness was noted in the medical record. After one week the rats were grouped (3 rats/cage).

\subsection{Analysis}

\subsubsection{Radiological follow-up}

Radiographic views of the femur defects were performed immediately after surgery and at the end of the experiment using a Faxitron x-ray machine (Edimex, Le Plessis Grammoire, France).

\subsubsection{Micro computed tomography $(\mu \mathrm{CT})$}

At each time point (7, 14 and 21 days) the rats were sacrificed with carbon dioxide, the femurs were dissected and fixed in $10 \%$ buffered formalin. Micro computed tomography $(\mu \mathrm{CT})$ imaging of whole femur was performed using a high-resolution $\mu$ CT scanner (Skyscan 1173, Synergie4, Evry, France) at a voltage of $90 \mathrm{kV}$, current of $88 \mathrm{~mA}$, isotropic pixel size of 12.1 $\mu \mathrm{m}$, exposure time $250 \mathrm{~ms}$ and $1 \mathrm{~mm}$-thick aluminum filter for beam hardening reduction. Three-dimensional reconstructions of the defect zones were obtained using N-Recon software and the CTAn software (Bruker) was used to define the region of interest with a specific orientation. The 3D image analysis was performed using the Matlab software (R2017b) with the Image Processing Toolbox.

\subsubsection{Magnetic resonance imaging (MRI)}

Magnetic resonance imaging was performed on 7- and 21-days-old rats (control and ACC/CDA groups, total $=8$ ) using a very high field MRI scanner operating at 17.6 T (Bruker magnet and Bruker Avance III HD console, Karlsruhe, Germany). The scanner is equipped with a threeaxis micro-imaging system (Bruker Micro 2.5, Karlsruhe, Germany) allowing a magnetic field 
gradient strength up to $1.5 \mathrm{~T} / \mathrm{m}$, and a $10 \mathrm{~mm}{ }^{1} \mathrm{H} /{ }^{31} \mathrm{P}$ birdcage resonator (Bruker MicWB40). Bone blocks of $5 \mathrm{~mm}$ including the holes were plunged into a (hydrogen-free) fluorinated oil (Halocarbon oil 700, Sigma Aldrich, France) to minimize magnetic susceptibility and to prevent the sample from drying. ${ }^{1} \mathrm{H}$ three-dimensional images were obtained using the Zero echo Time (ZTE) sequence [25] which allows imaging both the soft tissues and the mineral part of the bone. The 3D images were acquired with a field of view of $10 \times 10 \times 10 \mathrm{~mm}^{3}$, an isotropic voxel size of $(50 \mu \mathrm{m})^{3}$ in c.a. $24 \mathrm{~h}$, and processed with the Paravision 6 software (Bruker, Karlsruhe, Germany).

\subsubsection{Histological studies}

For histological analyses, all the femurs were partially decalcified in $10 \%$ (w/v) ethylenediaminetetraacetic acid solution for 8 weeks. Bone blocks of $5 \mathrm{~mm}$ including the holes and the patches were then cut at the distal femoral metaphysis and embedded in paraffin. For each block 2 sections of $10 \mu \mathrm{m}$ were made every $100 \mu \mathrm{m}$ from its beginning to its end. These sections were stained with hematoxylin and eosin (HE) and the slides were scanned using the Vectra Polaris automated quantitative pathology imaging system (PerkinElmer, Villebon-surYvette, France). Analysis and pictures were carried out using the Phenochart software.

\subsubsection{Statistical analyses}

Micro computed tomography data were statistically analyzed using the Student test and differences were considered statistically significant at $* p<0.05$ or $* * p<0.01$. For each group $\mathrm{n}=7$ or $\mathrm{n}=8$ at 7,14 and 21 days.

\section{Results}

\subsection{Animal follow up}

All the animals but two recovered uneventfully from the anesthetic and immediately led normal active lives with the operated limbs functioning normally. A total of 68 out of 72 operated 
femurs were analyzed (Table 1). During the dissection, macroscopic examination revealed no inflammatory reaction and no sign of patch rejection. Neither migration nor degradation of ACC was observed at any time point. The patches appeared colonized by a biological tissue and strongly adhesive to bone since patch release required to dissect this tissue.

\subsection{Bone defect healing analysis}

At day 7-post surgery, $\mu \mathrm{CT}$ and MRI analyses (Fig. 2A, 2B, and 2F) revealed the formation of new woven bone mixed with soft tissues inside the femur shaft for all the groups (control, ACC, and $\mathrm{ACC} / \mathrm{CDA})$. Although it cannot be stated firmly, this new bone seems to originate from the walls of the cortical bone, and to grow toward the defect. Three quantification parameters were defined from $\mu \mathrm{CT}$ images: (i) the volume ratio between the new bone and the total bone, (ii) the distance $(d)$ between the new bone front and the cortical bone surface (see Fig. 2B), and (iii) the cortical defect filling ratio (Fig. 2C, 2D and 2E, respectively). First, no significant difference of the bone volume ratio was observed between the three conditions (Fig. 2C). Conversely, data shown in the Fig. 2D indicated that the new bone front was closer to bone defect surface in the presence of a patch, and that this difference was statistically significant for ACC/CDA patches. Furthermore, it was revealed that cortical defect filling increased in the presence of a patch, ACC and ACC/CDA, and that this difference was statistically significant (Fig. 2E). Histological data (Fig. 2G) confirmed that new bone progressed more rapidly in the presence of a patch since new trabecular bone front, represented by a black dotted line, was closer to the bone surface (yellow dotted double arrow) in the presence of ACC (middle panel) and ACC/CDA (right panel) compared to control (left panel). Histological analysis also revealed that ACC/CDA patches were always tightly attached to the defect edges (Fig. $2 \mathrm{G}$ right panel) whereas a gap was almost always observed between the ACC patches and the bone defect

(Fig. 2, middle panel, double black arrow) suggesting more adhesive properties provided by CDA coating. 
(A)

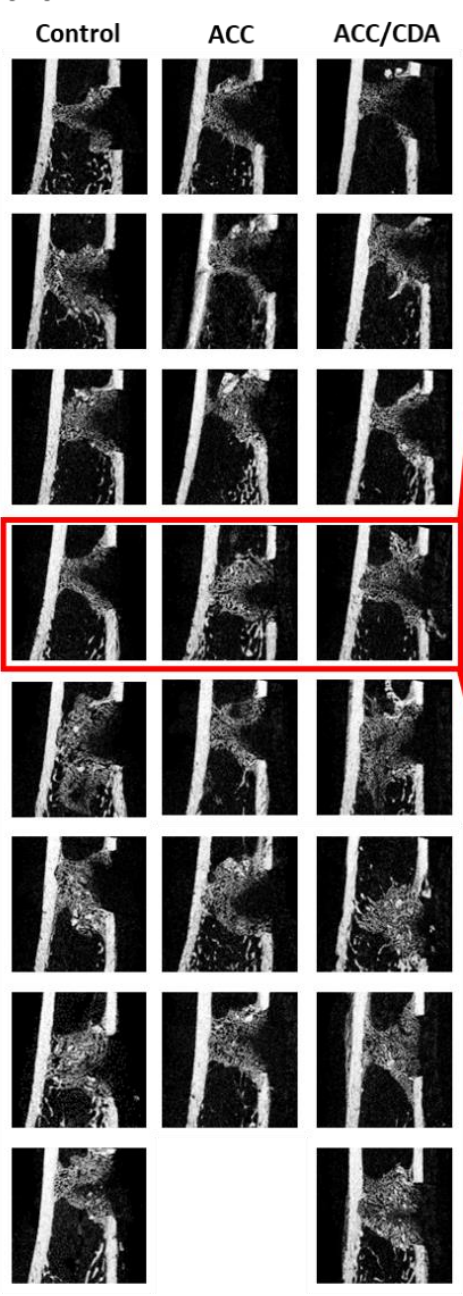

(D)

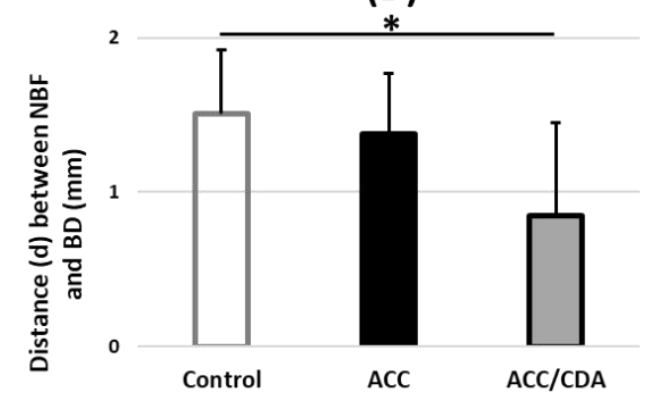

(F)

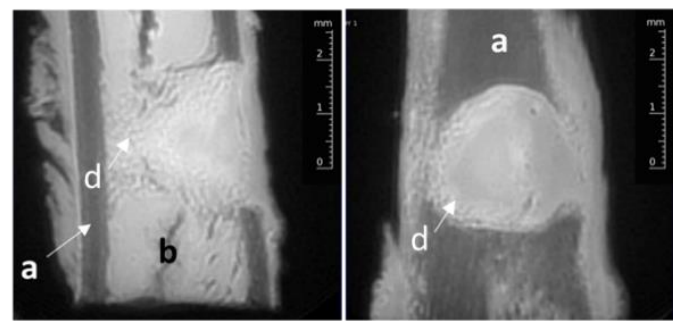

(B)

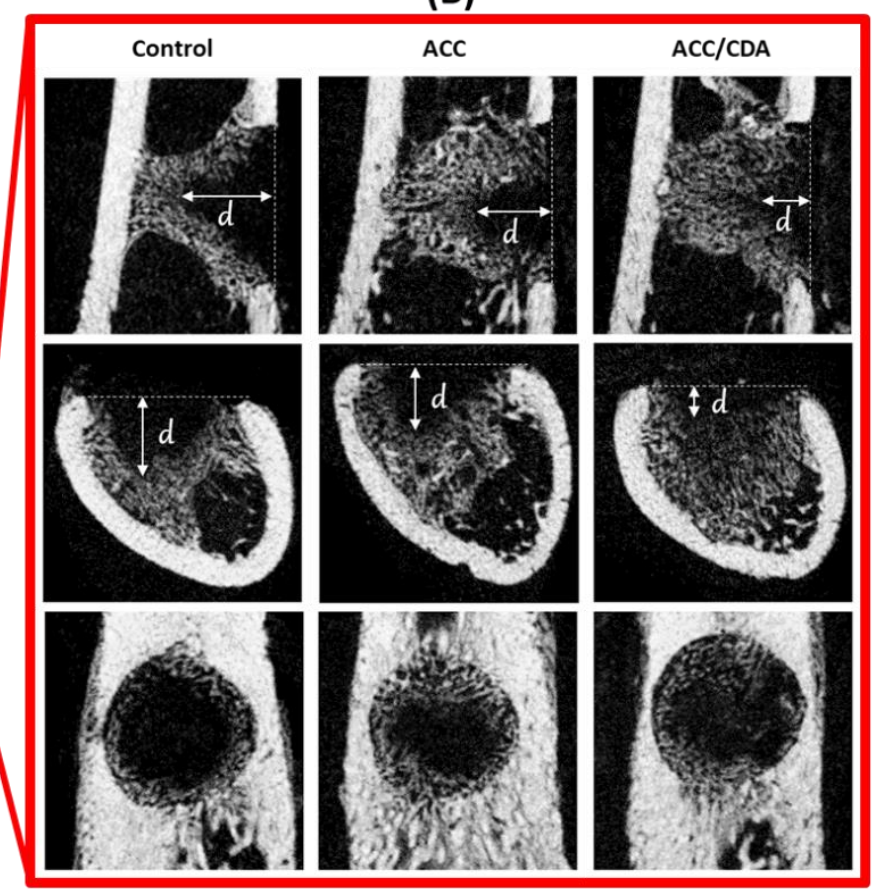

(C)

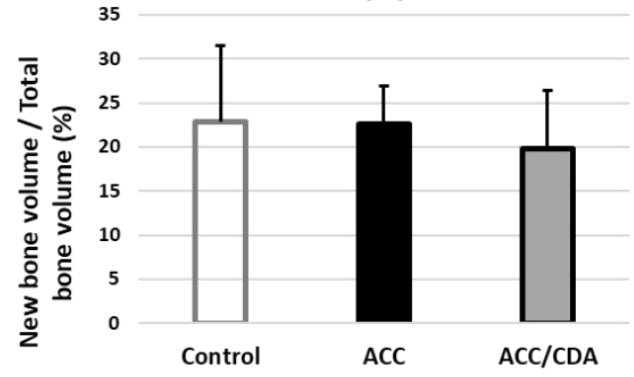

(E)

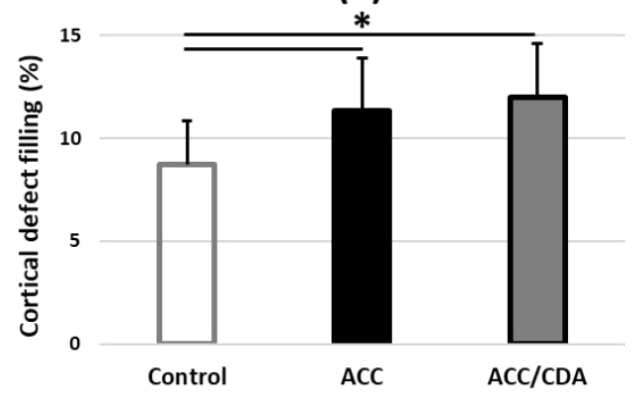

ACC/CDA

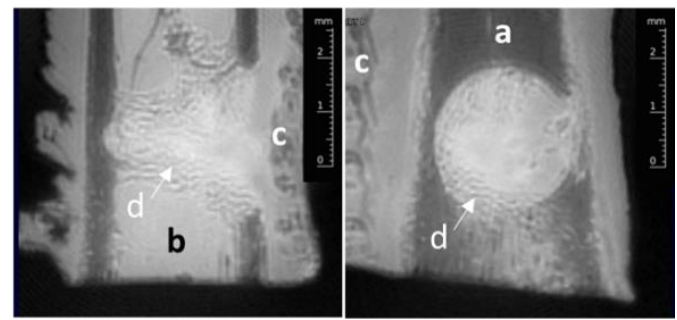

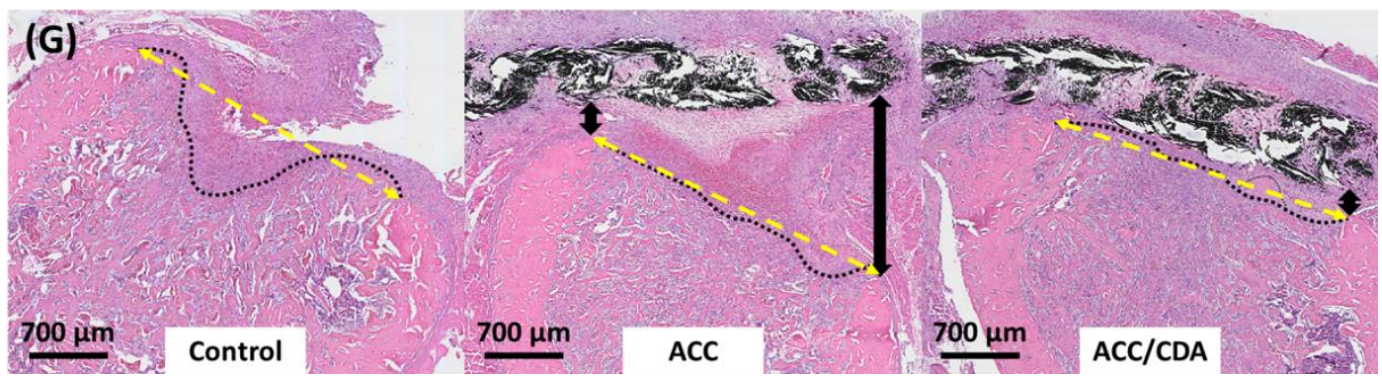


Fig. 2 Analysis of bone defect healing at day 7-post surgery. (A) $\mu \mathrm{CT}$ scan pictures of all the femurs in control, ACC and ACC/CDA groups. (B) Higher magnification of $\mu$-CT scan pictures of the representative samples for each group. Bone defect (BD) is delimited by a white dotted line, distance (d) between new bone front (NBF) and BD surface is schematized by a double white arrow. (C) Quantitative ratio between new bone and total bone volumes. (D, E): Quantification of (D) distance d, and (E) cortical defect filling. Mean \pm standard deviation, *p $<0.05$. (F) MRI images of two representative samples: control group (left image) and ACC/CDA group (right image); Bone cortical (a), bone marrow (b), ACC/CDA (c) and new woven bone and biological tissue mixture (d) are indicated. (G) Histological analysis of bone healing in the control (left), ACC (middle) and ACC/CDA (right) groups. Bone defect edges are linked by a yellow dotted double arrow, new bone growth front is visualized by a black dotted line and the gap between patch and bone defect is indicated by a black double arrow (scale bar $=700 \mu \mathrm{m})$.

At day 14-post surgery (Fig. 3) $\mu \mathrm{CT}$ analysis of the femurs showed that woven new bone has almost completely colonized the cortical defect (Fig. 3A, 3B). Interestingly, some new bone observed at the opposite cortical at day 7 has disappeared, suggesting a progressive displacement of new bone toward the defect. Quantitative data revealed that, like at day 7, new bone volume was similar for each group (Fig. 3C) but differences in bone shape were visible. In half of the femurs of the control group a depression of the bone surface was visible, and the new cortical was concave compared to ACC and ACC/CDA groups (Fig. 3A) despite similar amount of cortical defect filling for the three groups (Fig. 3D). Histological analysis (Fig. 3E) confirmed the influence of the patches on new bone shape and revealed that the new cortical was completely reconstituted especially in the presence of an ACC/CDA patch whereas a slight concavity at the defect zone still persisted in the controls (Fig. 3E, dotted line). These data also showed that a gap between ACC patches and femurs was still present, but was smaller compared with day 7 (see Fig. 3E, middle panel, black double arrow). 
(A)
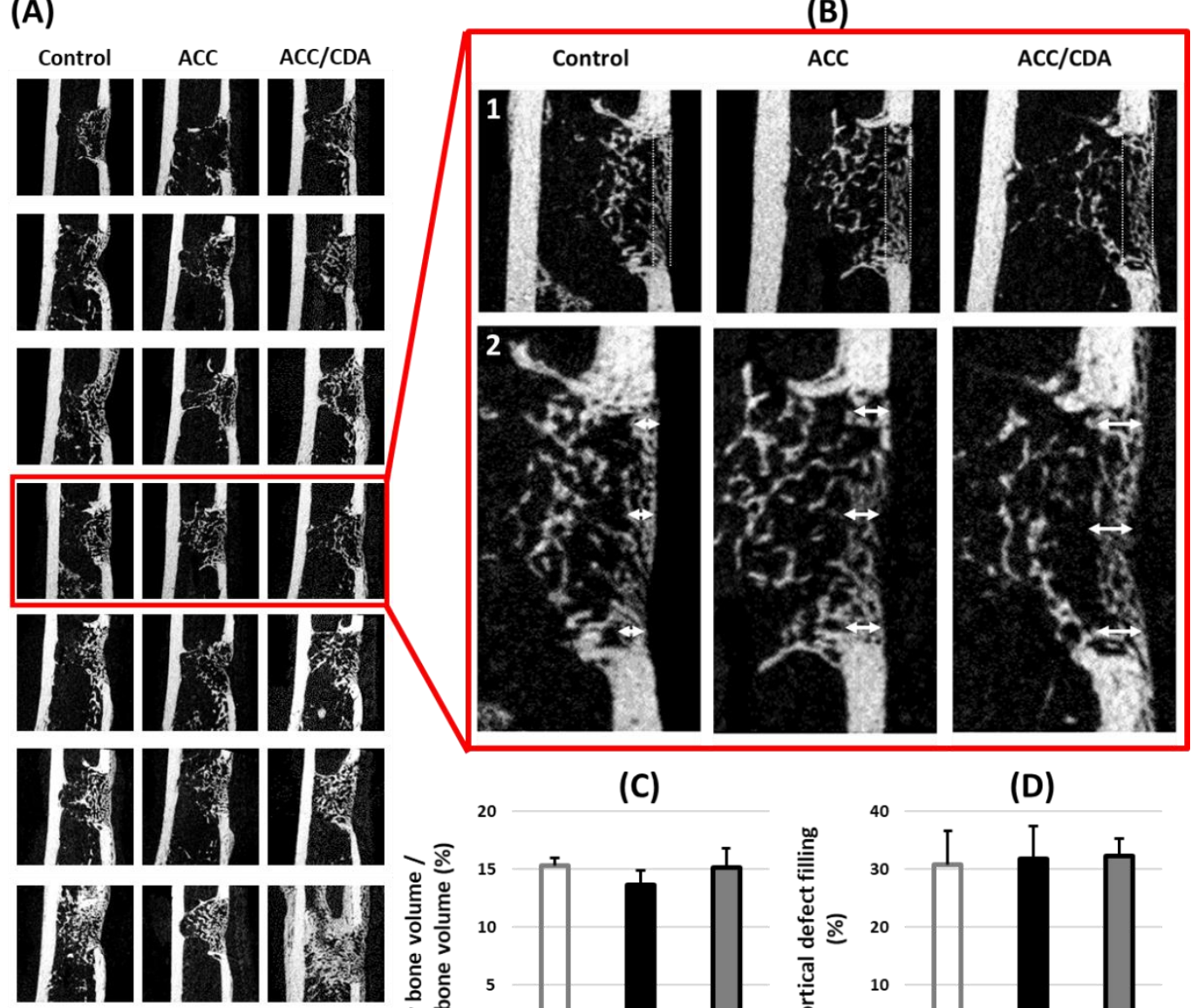

(C)

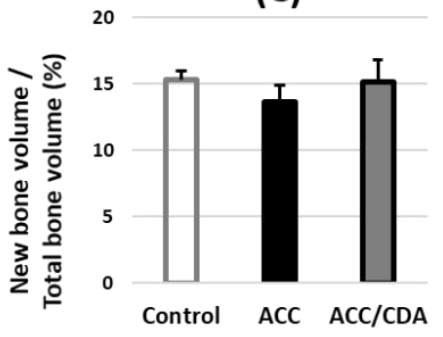

(D)
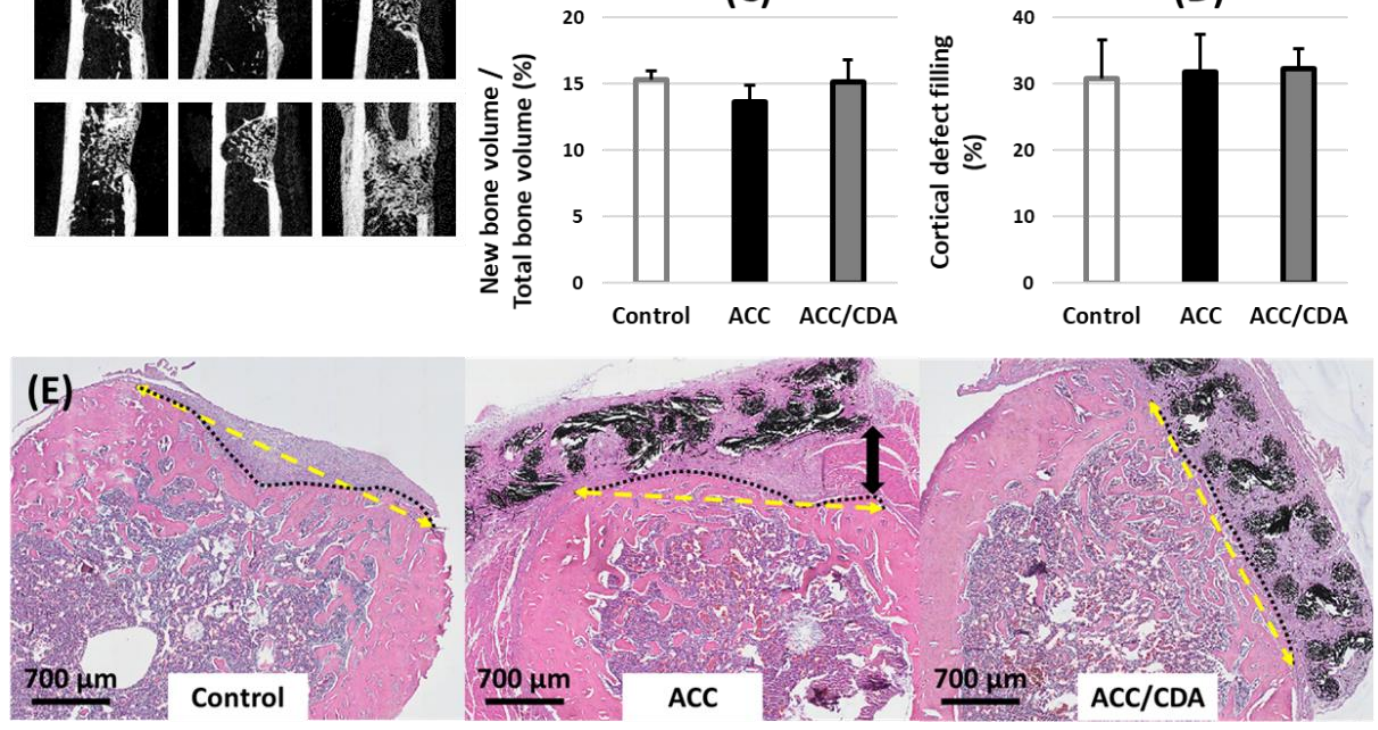

Fig. 3 Analysis of bone healing at day 14-post surgery. (A) $\mu \mathrm{CT}$ scan pictures of all the femurs in the three groups: control, ACC and ACC/CDA. The most representative sample of each group is framed in red. (B) Higher magnification of the $\mu$-CT scan pictures of the representative samples: (1) coronal view of cortical bone formation limited with white dotted line and (2) coronal views showing the thickness of the new cortical (double white arrow). (C) Quantitative ratio between new bone and total bone volumes and (D) quantification of cortical defect filling. (E) Histological analysis of bone defect. Bone defect edges are linked by a yellow dotted double arrow, new bone growth front is visualized by a black dotted line and the gap between patch and bone defect is indicated by a black double arrow. (Scale bar $=700 \mu \mathrm{m}$ ). 
At day 21-post surgery $\mu \mathrm{CT}$ and MRI analyses showed a densification of new bone in the cortical defect (Fig. 4A, 4B, and 4D). As observed at day 14, the new bone seemed to have moved toward the cortical defect because most of the woven bone has become sparse inside the shaft. Quantitative data indicated that the amount of new bone was similar in the three groups (Fig. 4A and C) but differences in bone shape were also visible (Fig. 4A and B). For all the defects covered with a patch the shape of the new cortical was perfectly convex like the native cortical. Conversely in half of the femurs of the control group a small depression of bone surface was still visible and the new cortical remained slightly concave (Fig. 4B1, 4B2, 4B3, see the white arrow). Histological results (Fig. 4E) also showed that a new cortical was formed in the three groups and that a little concavity was still observed in half of the control that did not receive any patch. 
(A)

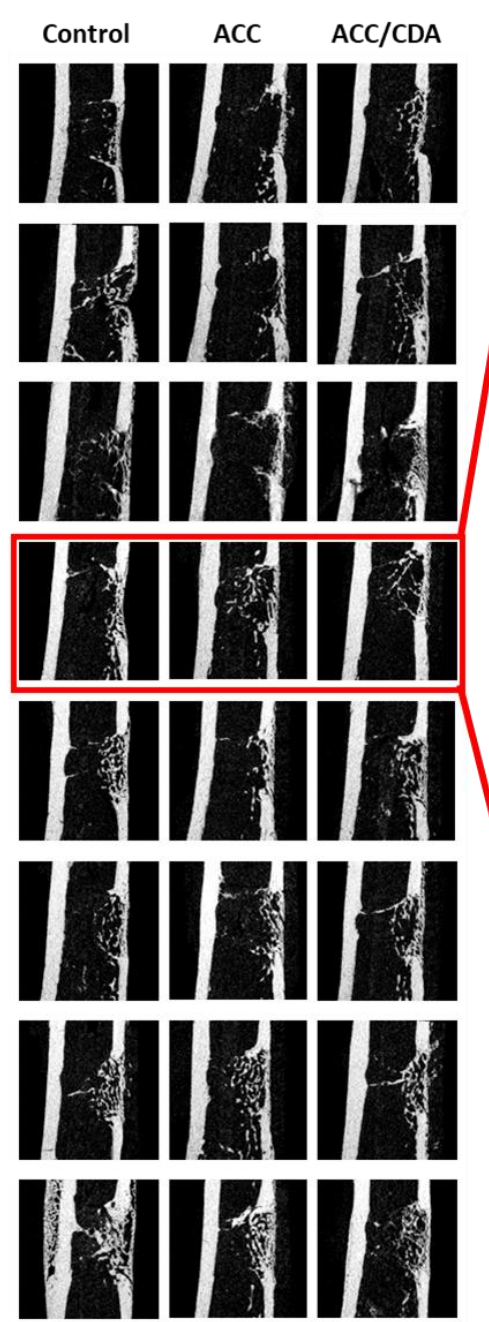

(C)

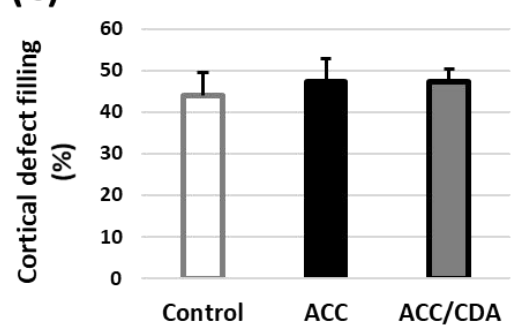

(B)

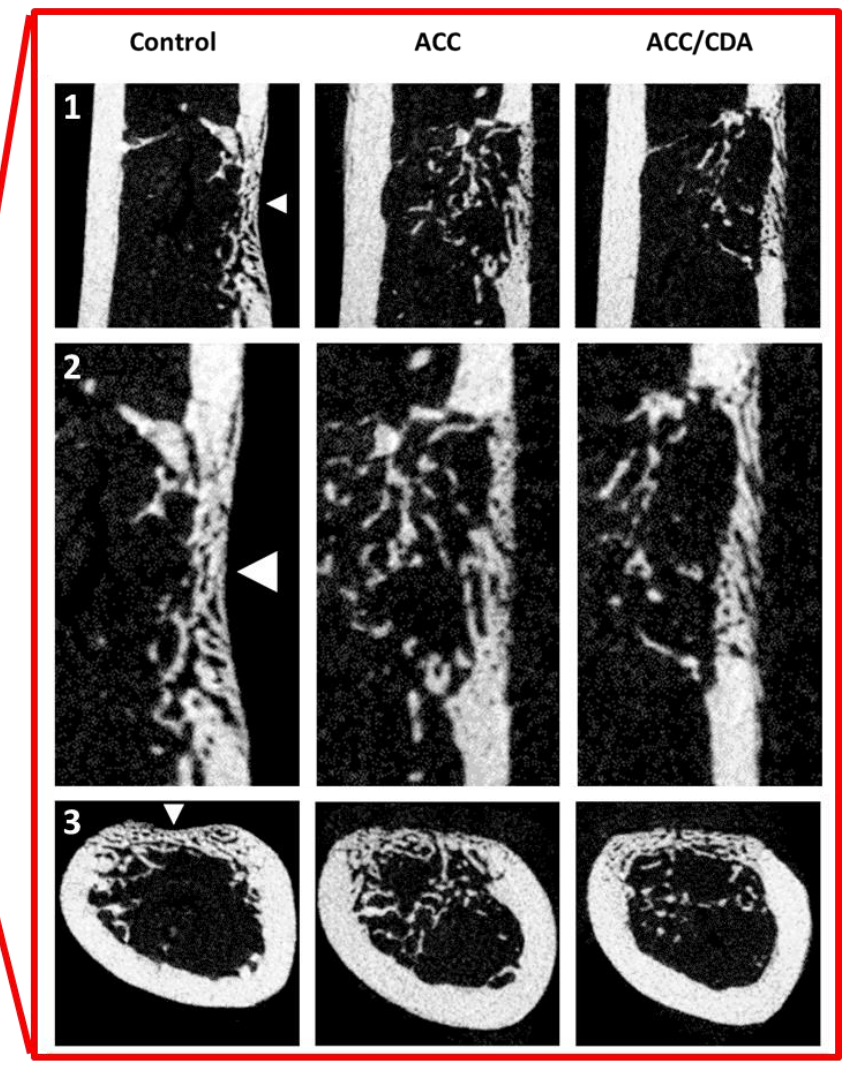

(D)

Control

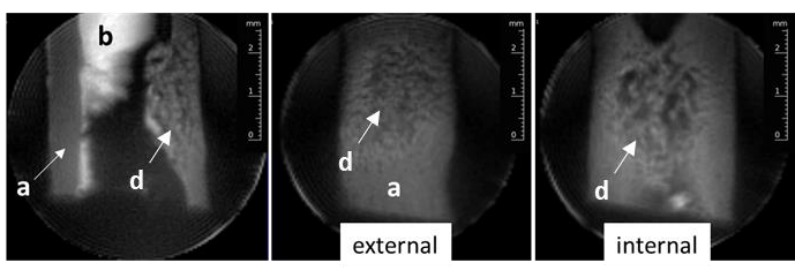

$\mathrm{ACC} / \mathrm{CDA}$

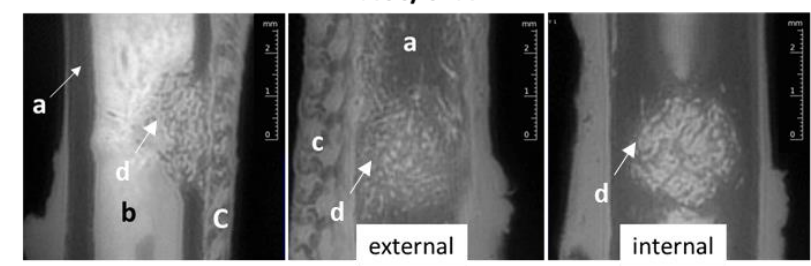

(E)

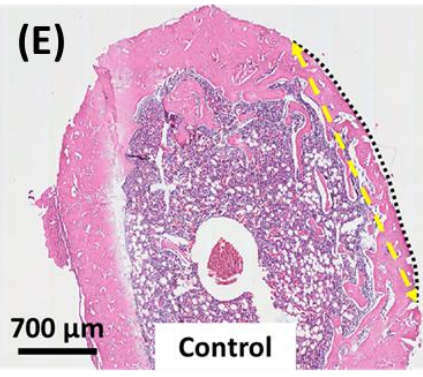

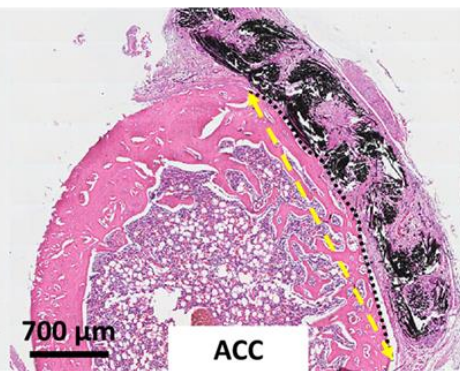

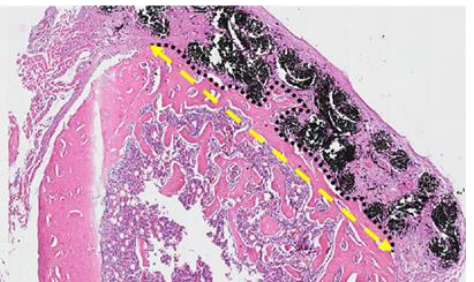

$700 \mu \mathrm{m}$

ACC/CDA

Fig. 4 Analysis of bone healing at day 21-post surgery. (A) $\mu \mathrm{CT}$ scan pictures of all the femurs in control, ACC and ACC/CDA groups. The most representative sample in each group is framed in red. (B) Higher magnification of $\mu$-CT scan pictures for the representative samples: (1) and (2) correspond to coronal views of the bone defect and (3) corresponds to transverse 
views of the bone defect. The presence of a slight depression at bone surface in the control group is indicated (white arrowhead). (C) Quantification of cortical defect filling. (D) MRI images of two representative samples: control group (top image) and ACC/CDA group (bottom image); Bone cortical (a), bone marrow (b), ACC/CDA (c) and new woven bone and biological tissue mixture (d). (E) Histological analysis of bone defect healing. Bone defect edges are linked by a yellow dotted double arrow, new bone growth front is visualized by a black dotted line. $($ Scale bar $=700 \mu \mathrm{m})$.

Cortical reconstruction was further analyzed (Fig. 5) from sagittal views of the $\mu \mathrm{CT}$ scan images (Fig. 5B) by quantifying its external (Fig. 5C) and internal surfaces (Fig. 5D) as schematized in Fig. 5A. Pictures shown in Fig. 5B indicated that at day 7-post surgery, reconstruction of the external surfaces was significantly higher in the presence of a patch compared with control and that this difference was higher in the presence of ACC/CDA compared with ACC. At day 14-post surgery, only the new cortical formed in the presence of ACC/CDA patches was homogeneously distributed whereas areas of missing bone were still visible in the control and ACC groups (Fig. 5B2, white arrow). At day 21-post surgery, both patches were associated with full regeneration. Conversely, in the control, areas of missing bone were still observed (see white arrow in Fig. 5B3). Quantification (Fig. 5C) of these results confirmed that the presence of a patch significantly accelerated external cortical reconstruction at day 7 and day 14 with better results with ACC/CDA compared with ACC (6\% vs $4 \%$ at day 7 and $77 \%$ vs. $73 \%$ at day 14). At day 21, no statistically significant difference was observed between the three groups. In the same line, measurements of the internal surface of the cortex (Fig. 5D) indicated that at day 7 and day 14 ACC/CDA but not ACC patches significantly accelerate bone formation. At day 21 no significant differences were observed between the three groups. 


\section{(A)}
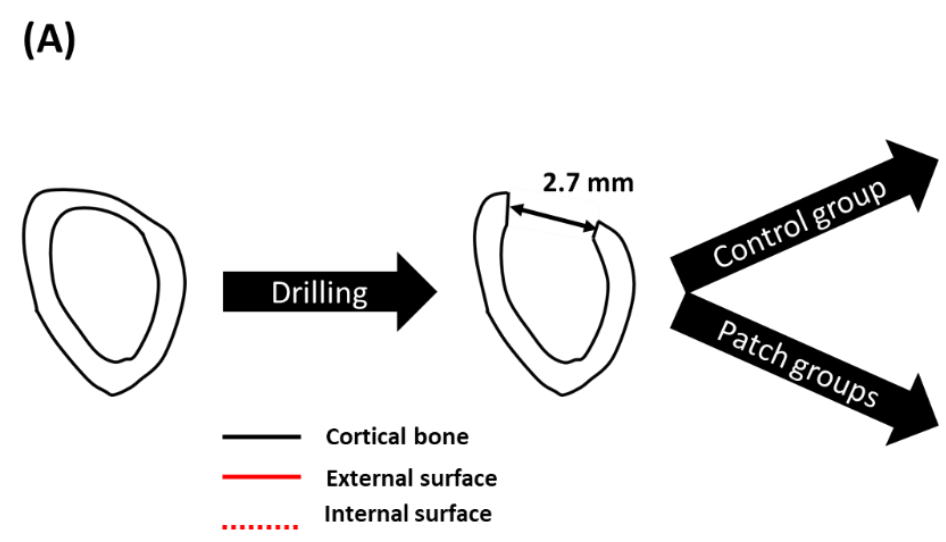

Transverse view
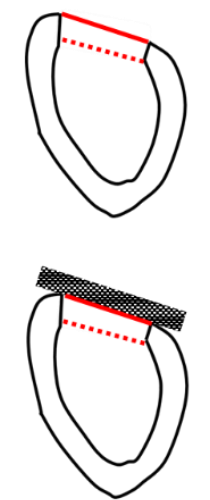

Coronal view
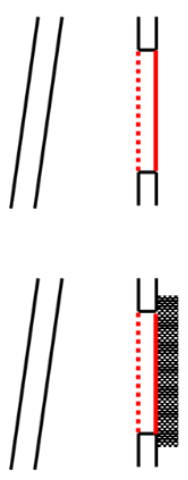

(B) Sagittal view: External surface
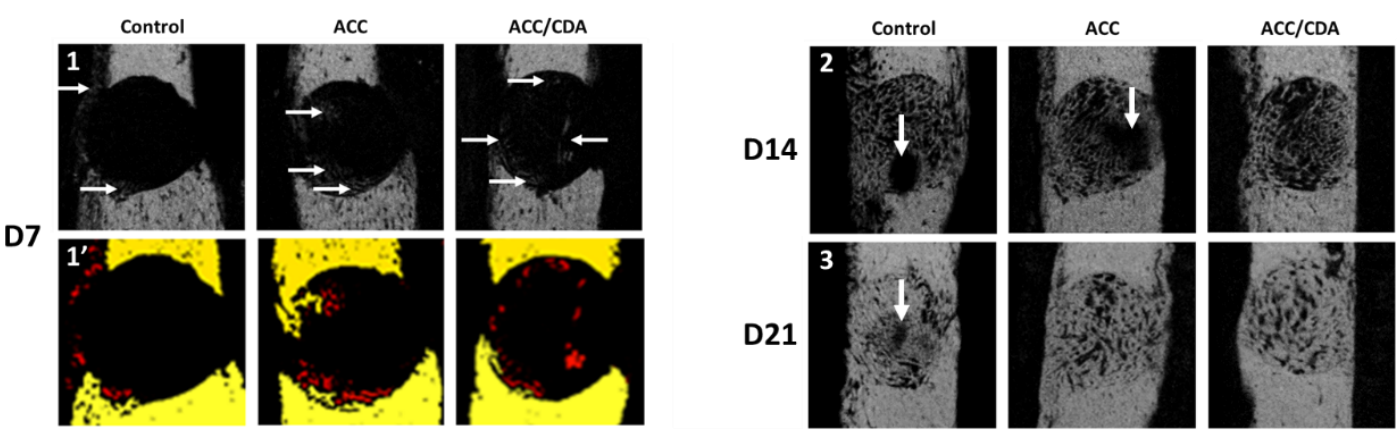

(C) External surface

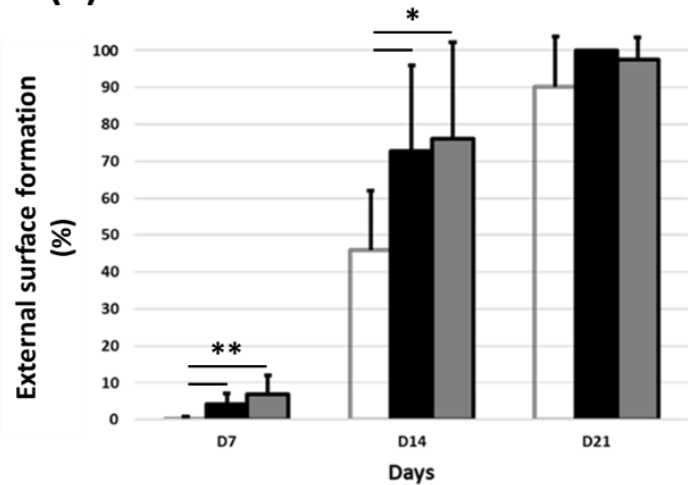

(D) Internal surface

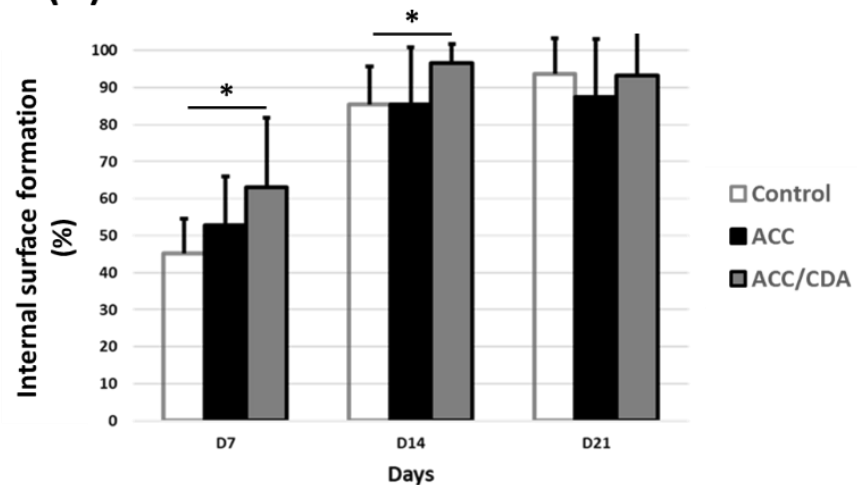

Fig. 5 Further analysis of cortical reconstruction at day 7, 14 and 21-post surgery. (A) Evaluation of bone formation at the external and internal surfaces of the cortical were made as schematized. (B) Sagittal views of the external surface of the representative samples of each group at 7, 14 and 21 days. The white arrows (B1) and the red color (B1') indicate the presence of new bone. (C, D) Quantification of new cortical bone formation (C) at the external surface and (D) at the internal surface. Mean \pm standard deviation, ${ }^{*} \mathrm{p}<0.05$, $* * \mathrm{p}<0.01$. 


\subsection{Examination of $\mathrm{ACC}$ and $\mathrm{ACC} / \mathrm{CDA}$ patches over time}

Light-microscopic examination of the patches at the different time points (Fig. 6) revealed differences between $\mathrm{ACC}$ and $\mathrm{ACC} / \mathrm{CDA}$ patches. At day 7-post surgery high rate of fibroblastic proliferation was observed in both carbon fiber cloth with a higher number of blood vessels in ACC/CDA (Fig. 6A and 6A'). Moreover, in one ACC/CDA patch a zone of woven bone was observed in the interspace between bone and patch (Fig. 6A'). At day 14-post surgery, in both patches the number of blood vessels increased and numerous osteoclast-like cells were observed (Fig. 6B and 6B'). In both patches the amount of woven bone present at the junction between patch and defect had increased, and this amount and its integration in the carbon tissue was higher in ACC/CDA compared with ACC patches (Fig. 6B'). This difference was also observed at day 21-post surgery since a large zone of mature bone including red bone marrow was present inside an ACC/CDA patch (Fig. 6C').
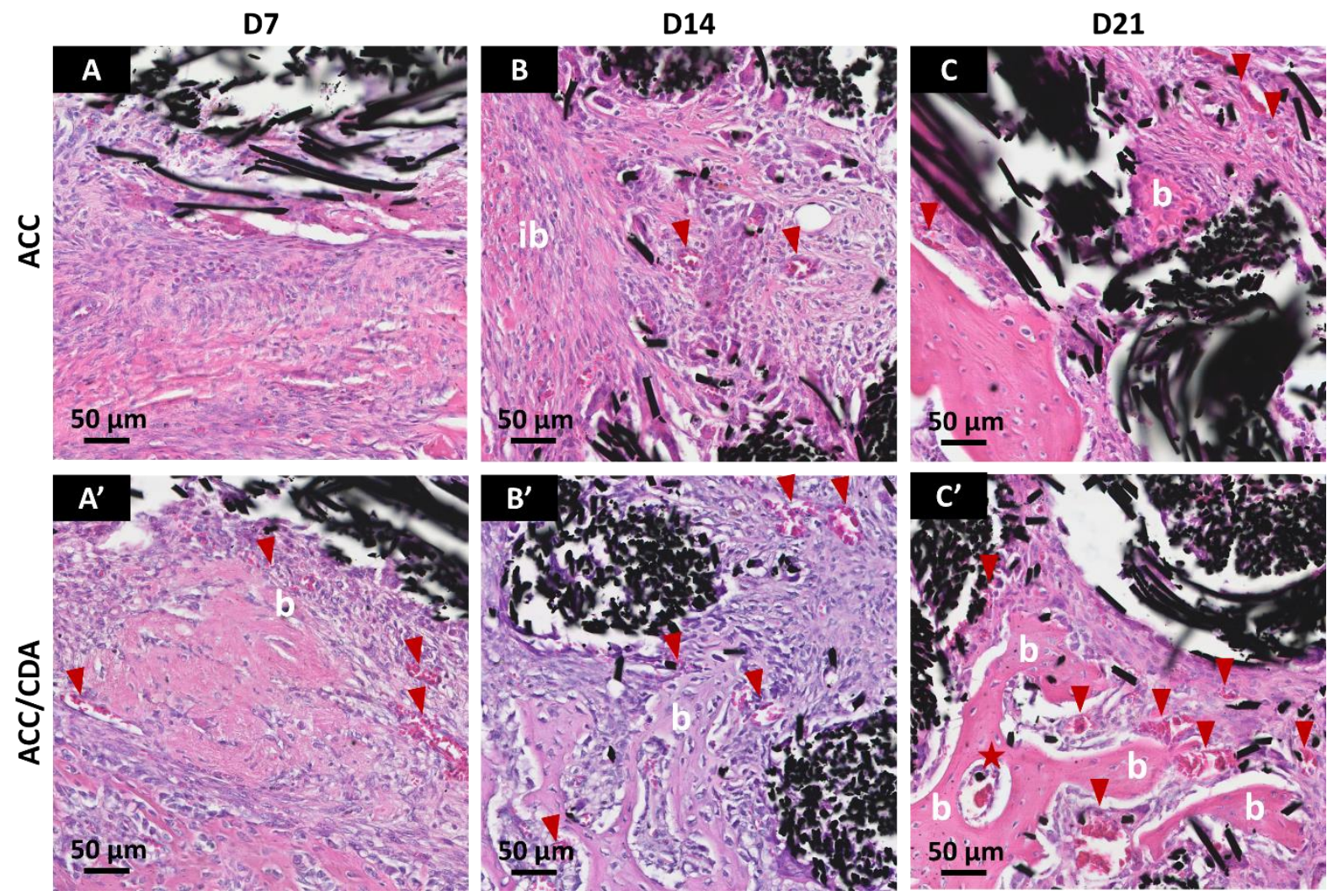

Fig. 6 Light-microscopic examination of ACC (A, B and C) and ACC/CDA (A', B' and C') patches at day 7, 14 and 21-post surgery. For each patch and at each time point a representative 
view of an area of interest is shown. The presence of large vessels or arterioles (red arrow head), bone marrow (red star), immature bone trabeculae (ib) and bone trabeculae (b) are reported.

\section{Discussion}

We have used a rat model to test the effectiveness of ACC and ACC/CDA materials in vivo. A bilateral cortical defect of $5.7 \mathrm{~mm}^{2}$ was created, corresponding to approximatively $25 \%$ of the femur circumference at its distal extremity. This cylindrical defect provides with a relatively large defect and allows to evaluate biomaterial effectiveness over a short period of 2 to 3 weeks. Moreover we found during the surgical procedure that one of the advantages of the ACC and ACC/CDA patches was the easiness of their use by simple apposition on the bone surface, with no need of sewing.

We show here that apposition of a patch consisting of carbon fiber cloth at the surface of a bone defect accelerates cortical bone healing and that carbonated calcium-deficient apatite (CDA) coating of the fibers optimizes this effect. These results are consistent with our previous works in which we demonstrated the feasibility to perform a homogeneous and uniform coating of CDA at the surface of ACC material [22,23] and that this CDA coating improves ACC biocompatibility toward primary human osteoblasts [24].

Acceleration of bone defect reconstruction in the presence of the patches was assessed by coupling different complementary techniques of analysis that is micro CT scan, MRI and histology, which all confirmed the positive effect of both materials at day 7 and day 14. CDA coated ACC was the most efficient material, providing with the highest effect on bone cortical reconstruction. This efficiency was observed on all the parameters that were measured such as distance between new bone front and bone defect surface, cortical bone filling as well as reconstruction of the internal and external surfaces of the cortical. Comparatively, the positive effect of the uncoated ACC patches was lower but statistically significant at day 7 and 14 on 
the reconstruction of the external surface of the cortical which was in contact with the patch. At day 21-post surgery, all the defects were closed in the three groups but the effect of the patches was still visible on cortical shape. Indeed, in the presence of ACC or ACC/CDA the newly formed cortical was perfectly convex, looking like its native shape, whereas a little concavity was still present in the controls.

These experiments thus revealed that apposition of a patch accelerates cortical bone closure. Since new bone volume was similar in the three conditions, this strongly suggests that the presence of a patch induces a faster vectorization of new bone formation. The patches likely provide with an efficient support for new bone growth, guiding bone regeneration and inducing an optimal reconstruction of the cortical. This effect was both quantitative and qualitative. Effectiveness was quantitative since the distance between new bone front and bone surface was much smaller at day 7 in the presence of a patch. Moreover, the positive effect of the patches on the reconstruction of the external surface of the cortical at day 7 and 14 was demonstrated. It was also qualitative since bone shape was fully restored at day 21 only in the presence of a patch. These results are consistent with other studies which have demonstrated the beneficial role of different kind of membranes in guiding bone formation, providing with a support for precursor cell migration and proliferation [26]. In the present experiments the beneficial role of CDA coating on bone healing acceleration is likely due to the fact that the different compounds of CDA i.e. calcium, phosphate and carbonate ions, participate as precursors to bone mineral formation.

Over time, we have noticed that the volume of new bone decreased. This is consistent with fracture repair in which the reparative phase characterized by bony callus formation is followed by a remodeling phase. In this later phase, woven bone is progressively replaced by lamellar bone and the excess callus is resorbed leading to normal bone architecture [27,28]. 
Another beneficial effect of the patches could be their role as a physical barrier avoiding the bone marrow, which contains all bone cell precursors, to flow out of the defect. In this line the higher effect of the ACC/CDA compared with uncoated ACC patch could be related to its better adhesion to bone, a phenomenon that we observed at day 7 and to a lesser extent at day 14 . Indeed at these time points a gap was almost always observed between ACC patch and bone but never with ACC/CDA. CDA coating thus allowed to maintain a straight contact between path and bone compared to uncoated ACC. The strong adhesion of ACC/CDA to bone surface related to the CDA coating, is consistent with data showing that hydroxyapatite coating of orthopedic prosthesis induces a dramatic increase of their bone anchorage [29].

Besides a positive effect on bone reconstruction these experiments demonstrate for the first time in vivo the high biocompatibility of these ACC materials. We observed that the carbon fibers were progressively colonized by a very active fibrous tissue, many blood vessels and osteoclast-like cells. The ACC/CDA patches were also invaded by small trabeculae of mature bone including bone marrow. The presence of red bone marrow areas reveals the capacity of the new bone to sustain hematopoietic activity, which reflects its good quality and high regenerative properties, which is crucial for long term performance. Altogether these data demonstrate the very good osteointegration of the patches and again revealed an additional advantage CDA coating.

We evidence here in a rat model of large bone cortical defect, the interest of using activated carbon fiber cloth to accelerate bone healing. This study confirms their high biocompatibility and reveals their efficacy, especially for CDA coated forms, to regenerate cortical bone defects.

\section{Acknowledgements}


The authors are very grateful to Marielle Maret, Aurélia Errante, Jose-Rubi Correia-Merle and all the staff of animal facility for excellent animal care. The authors thank Florian Boukhechba, Samah Rekima, David Momier and all the staff of the IBV histology department for technical assistance.

This work was financially supported by the Region Centre-Val de Loire projects "MatCCaPBio" 2018-2021.

\section{References}

[1] M. Suzuki, Activated carbon fiber: Fundamentals and applications, Carbon. 32 (1994) 577-586. https://doi.org/10.1016/0008-6223(94)90075-2.

[2] E. Frank, L.M. Steudle, D. Ingildeev, J.M. Spörl, M.R. Buchmeiser, Carbon Fibers: Precursor Systems, Processing, Structure, and Properties, Angewandte Chemie International Edition. 53 (2014) 5262-5298. https://doi.org/10.1002/anie.201306129.

[3] Z. Yue, J. Economy, Carbonization and activation for production of activated carbon fibers, in: Activated Carbon Fiber and Textiles, Elsevier, 2017: pp. 61-139. https://doi.org/10.1016/B978-0-08-100660-3.00004-3.

[4] F. Rodríguez-Reinoso, A.C. Pastor, H. Marsh, M.A. Martínez, Preparation of activated carbon cloths from viscous rayon. Part II: physical activation processes, Carbon. 38 (2000) 379-395. https://doi.org/10.1016/S0008-6223(99)00118-9.

[5] F. Rodriguez-Reinoso, A.C. Pastor, H. Marsh, A. Huidobro, Preparation of activated carbon cloths from viscous rayon Part III. Effect of carbonization on $\mathrm{CO} 2$ activation, (2000) 10.

[6] R. Leyva-Ramos, R. Ocampo-Perez, J. Mendoza-Barron, External mass transfer and hindered diffusion of organic compounds in the adsorption on activated carbon cloth, $\begin{array}{lllll}\text { Chemical Engineering } & \text { Journal. } & 183 & \text { (2012) }\end{array}$ https://doi.org/10.1016/j.cej.2011.12.046.

[7] S. Masson, M. Gineys, S. Delpeux-Ouldriane, L. Reinert, S. Guittonneau, F. Béguin, L. Duclaux, Single, binary, and mixture adsorption of nine organic contaminants onto a microporous and a microporous/mesoporous activated carbon cloth, Microporous and $\begin{array}{lllll}\text { Mesoporous } & \text { Materials. } & 234 & \text { (2016) }\end{array}$ https://doi.org/10.1016/j.micromeso.2016.07.001.

[8] C. Nieto-Delgado, D. Partida-Gutierrez, J.R. Rangel-Mendez, Preparation of activated carbon cloths from renewable natural fabrics and their performance during the adsorption of model organic and inorganic pollutants in water, Journal of Cleaner Production. 213 (2019) 650-658. https://doi.org/10.1016/j.jclepro.2018.12.184.

[9] D. Adams, D.F. Williams, J. Hill, Carbon fiber-reinforced carbon as a potential implant material, Journal of Biomedical Materials Research. 12 (1978) 35-42. https://doi.org/10.1002/jbm.820120104.

[10] R.J. Minns, D.S. Muckle, J.E. Donkin, The repair of osteochondral defects in osteoarthritic rabbit knees by the use of carbon fibre, Biomaterials. 3 (1982) 81-86. https://doi.org/10.1016/0142-9612(82)90038-2. 
[11] R.J. Minns, D.S. Muckle, Mechanical and histological response of carbon fibre pads implanted in the rabbit patella, Biomaterials. 10 (1989) 273-276. https://doi.org/10.1016/0142-9612(89)90105-1.

[12] A. Carranza-Bencano, J.R. Armas-Padro, Carbon fiber implants in osteochondral defects of the rabbit patella, (2000) 6 .

[13] A. Slosarczyk, M. Klisch, M. Blazewicz, J. Piekarczyk, L. Stobierski, A. Rapacz-Kmita, Hot pressed hydroxyapatite-carbon fibre composites, Journal of the European Ceramic Society. (2000) 1397-1402.

[14] M. Wu, Q. Wang, X. Liu, H. Liu, Biomimetic synthesis and characterization of carbon nanofiber/hydroxyapatite composite scaffolds, Carbon. 51 (2013) 335-345. https://doi.org/10.1016/j.carbon.2012.08.061.

[15] X. Wang, X. Zhao, W. Wang, J. Zhang, L. Zhang, F. He, J. Yang, Controllable preparation of a nano-hydroxyapatite coating on carbon fibers by electrochemical deposition and chemical treatment, Materials Science and Engineering: C. 63 (2016) 96-105. https://doi.org/10.1016/j.msec.2016.02.058.

[16] X. Wang, X. Zhao, L. Zhang, W. Wang, J. Zhang, F. He, J. Yang, Design and fabrication of carbon fibers with needle-like nano-HA coating to reinforce granular nano-HA composites, Materials Science and Engineering: C. 77 (2017) 765-771. https://doi.org/10.1016/j.msec.2017.03.307.

[17] X. Zhao, X. Wang, H. Xin, L. Zhang, J. Yang, G. Jiang, Controllable preparation of SiC coating protecting carbon fiber from oxidation damage during sintering process and $\mathrm{SiC}$ coated carbon fiber reinforced hydroxyapatite composites, Applied Surface Science. 450 (2018) 265-273. https://doi.org/10.1016/j.apsusc.2018.04.164.

[18] L.L. Hench, Bioceramics: From Concept to Clinic, Journal of the American Ceramic Society. 74 (1991) 1487-1510. https://doi.org/10.1111/j.1151-2916.1991.tb07132.x.

[19] M.G.S. Murray, J. Wang, C.B. Ponton, P.M. Marquis, An improvement in processing of hydroxyapatite ceramics, Journal of Materials Science. 30 (1995) 3061-3074. https://doi.org/10.1007/BF01209218.

[20] H. Li, X. Zhao, S. Cao, K. Li, M. Chen, Z. Xu, J. Lu, L. Zhang, Na-doped hydroxyapatite coating on carbon/carbon composites: Preparation, in vitro bioactivity and biocompatibility, Applied Surface Science. $263 \quad$ (2012) 163-173. https://doi.org/10.1016/j.apsusc.2012.09.022.

[21] S. Kobayashi, W. Kawai, Development of carbon nanofiber reinforced hydroxyapatite with enhanced mechanical properties, Composites Part A: Applied Science and Manufacturing. 38 (2007) 114-123. https://doi.org/10.1016/j.compositesa.2006.01.006.

[22] Q. Picard, F. Olivier, S. Delpeux, J. Chancolon, F. Warmont, S. Bonnamy, Development and Characterization of Biomimetic Carbonated Calcium-Deficient Hydroxyapatite Deposited on Carbon Fiber Scaffold, C. 4 (2018) 25. https://doi.org/10.3390/c4020025.

[23] F. Olivier, Q. Picard, S. Delpeux-Ouldriane, J. Chancolon, F. Warmont, V. Sarou-Kanian, F. Fayon, S. Bonnamy, Influence of electrochemical parameters on the characteristics of sono-electrodeposited calcium phosphate-coated carbon fiber cloth, Surface and Coatings Technology. 389 (2020) 125507. https://doi.org/10.1016/j.surfcoat.2020.125507.

[24] F. Olivier, N. Rochet, S. Delpeux-Ouldriane, J. Chancolon, V. Sarou-Kanian, F. Fayon, S. Bonnamy, Strontium incorporation into biomimetic carbonated calcium-deficient hydroxyapatite coated carbon cloth: Biocompatibility with human primary osteoblasts, Materials Science and Engineering: C. $116 \quad$ (2020) 111192. https://doi.org/10.1016/j.msec.2020.111192.

[25] M. Weiger, K.P. Pruessmann, MRI with Zero Echo Time, in: R.K. Harris (Ed.), Encyclopedia of Magnetic Resonance, John Wiley \& Sons, Ltd, Chichester, UK, 2012. https://doi.org/10.1002/9780470034590.emrstm1292. 
[26] I. Elgali, O. Omar, C. Dahlin, P. Thomsen, Guided bone regeneration: materials and biological mechanisms revisited, Eur J Oral Sci. 125 (2017) 315-337. https://doi.org/10.1111/eos.12364.

[27] T.A. Einhorn, L.C. Gerstenfeld, Fracture healing: mechanisms and interventions, Nat Rev Rheumatol. 11 (2015) 45-54. https://doi.org/10.1038/nrrheum.2014.164.

[28] J.A. Cottrell, J.C. Turner, T.L. Arinzeh, J.P. O'Connor, The Biology of Bone and Ligament Healing, Foot and Ankle Clinics. 21 (2016) 739-761. https://doi.org/10.1016/j.fcl.2016.07.017.

[29] S. Eto, H. Miyamoto, T. Shobuike, I. Noda, T. Akiyama, M. Tsukamoto, M. Ueno, S. Someya, S. Kawano, M. Sonohata, M. Mawatari, Silver oxide-containing hydroxyapatite coating supports osteoblast function and enhances implant anchorage strength in rat femur: SILVER OXIDE-CONTAINING HYDROXYAPATITE COATING, J. Orthop. Res. 33 (2015) 1391-1397. https://doi.org/10.1002/jor.22903. 